\title{
LETTER
}

\section{Serum miR-122 correlates with short-term mortality in sepsis patients}

\author{
Huijuan Wang ${ }^{1,2+}$, Bingxiang Yü ${ }^{3+}$, Jie Deng ${ }^{4}$, Yang Jin ${ }^{5^{*}}$ and Lixin Xie ${ }^{1 *}$
}

Sepsis is one of the leading causes of death in the ICU. The pathogenesis of sepsis remains incompletely understood, thereby impeding the development of therapeutics, diagnostics and biomarkers to predict outcomes [1]. Our previous studies have proved that miR-122, miR-193b*, miR-483-5p and miR-574-5p were all differentially expressed between sepsis survivors and non-survivors, differentiated by 28 -day mortality $[2,3]$. However, whether these biomarkers related to patients with both sepsis and acute respiratory distress syndrome (ARDS) remains unclear. Here we evaluate the levels of these four microRNAs (miRNAs) along with C-reactive protein (CRP), procalcitonin (PCT), Sequential Organ Failure Assessment (SOFA) score, and Acute Physiology and Chronic Health Evaluation (APACHE) II score to determine the ideal biomarkers for sepsis patients.

Serum samples were collected from 232 sepsis patients who were admitted to ICUs of the Chinese PLA General Hospital. All the patients met the definition of sepsis developed in 2003 [4]. Inclusion and exclusion criteria are described in Table 1. Another 24 normal individuals were also included in this study. Serum levels of miRNAs, CRP and PCT were analyzed using methods as described in detail previously [3]. This study was approved by the ethics committee of the Chinese PLA General Hospital.
Appropriate informed consent was obtained from each patient and normal individual.

The clinical data of these 232 patients are shown in Table 2. After comparison of the levels of the four miRNAs in three pairs of groups (normal individuals and sepsis patients, survivors and non-survivors, sepsis without ARDS and sepsis plus ARDS), only the cycle threshold of mir-122 was differentially expressed in all three $(P<0.01)$ (Figure 1). Univariable and multivariable regression analyses were then used to evaluate the association between miR-122 and 28-day mortality in different ICUs. After adjustment using clinical data and additional parameters (SOFA score, APACHE II score and ARDS), the odds ratio of miR-122 association with 28-day mortality was around 0.376 to $0.868(P<0.05)$ in the different ICUs. The area under the curve for the predictive value of miR-122 was around 0.706 to $0.770(P<0.01)$ with high sensitivity and specificity (Table 3 ). As a result, only miR-122 can be used as a biomarker with regards to patients with both sepsis and ARDS. miR-122 is a liver-specific miRNA and levels of it in serum were correlated with drug-induced liver injury [5]. We reported that miR-122 correlated with coagulation disorders in sepsis patients and serum levels of miR-122 correlated with serum antithrombin III levels [6]. Our study reveals a potential novel target to develop a biomarker for sepsis prognosis and therapeutic strategies.

\footnotetext{
* Correspondence: yjin@rics.bwh.harvard.edu; xielx@263.net

${ }^{\dagger}$ Equal contributors

${ }^{5}$ Division of Pulmonary and Critical Care Medicine, Brigham and Women's Hospital, Harvard Medical School, Boston, MA 02115, USA

${ }^{1}$ Department of Respiratory Medicine, Chinese PLA General Hospital, 28th

Fuxing Road, Beijing 100853, PR China

Full list of author information is available at the end of the article
}

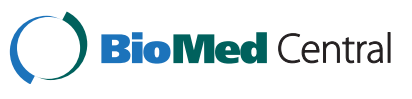




\section{Table 1 Inclusion and exclusion criteria}

\section{Inclusion criteria}

1) Sepsis patients all met the definitions of the 2001 SCCM/ESICM/

ACCP/ATS/SIS International Sepsis Definitions Conference [4]

\section{Exclusion criteria}

1) Patients who were younger than 18 years old

2) Patients who were immunosuppressed

3) Patients who did not receive adequate treatment

4) Patients who did not give their written informed consent

2) All patients received standard protocols of clinical care

Table 2 Clinical characteristics of the 232 sepsis patients

\begin{tabular}{|c|c|c|}
\hline Category & Variables & Sepsis $(n=232)$ \\
\hline \multirow[t]{2}{*}{ Demographic parameters } & Gender (male/female) & $169 / 63$ \\
\hline & Age in years (median (range)) & $59(19,91)$ \\
\hline \multirow[t]{15}{*}{ Clinical parameters } & ICU type & \\
\hline & Medical & $232(100 \%)$ \\
\hline & Cardiac & 79 (34.05\%) \\
\hline & Surgical & 95 (40.95\%) \\
\hline & Trauma & $25(10.77 \%)$ \\
\hline & Cancer & $24(10.34 \%)$ \\
\hline & Other & $15(6.46 \%)$ \\
\hline & APACHE II score & $18(1,39)$ \\
\hline & SOFA score & $7(0,19)$ \\
\hline & Acute kidney injury & $61(26.29 \%)$ \\
\hline & Mechanical ventilation & $171(73.71 \%)$ \\
\hline & Heat failure & $121(52.15 \%)$ \\
\hline & Liver failure & $103(44.39 \%)$ \\
\hline & ARDS & $60(28.17 \%)^{a}$ \\
\hline & 28-day mortality & $45.69 \%$ \\
\hline \multirow[t]{6}{*}{ Biomarkers } & miR-122 & $17.75 \pm 3.40$ cycles \\
\hline & miR-193b* & $17.73 \pm 4.81$ cycles \\
\hline & miR-574-5p & $21.19 \pm 3.64$ cycles \\
\hline & miR-483-5p & $18.99 \pm 4.24$ cycles \\
\hline & $\mathrm{CRP}(\mathrm{mg} / \mathrm{dl})$ & $8.9(0.1,35)$ \\
\hline & PCT (ng/ml) & $4.63(0.05,119.44)$ \\
\hline
\end{tabular}

${ }^{a}$ ARDS data of 19 patients were missing. APACHE, Acute Physiology and Chronic Health Evaluation; ARDS, acute respiratory distress syndrome; CRP, C-reactive protein; PCT, procalcitonin; SOFA, Sequential Organ Failure Assessment. APACHE II score, SOFA score, CRP and PCT are all given as median (range).

*ARDS data of 19 patients were missing. 


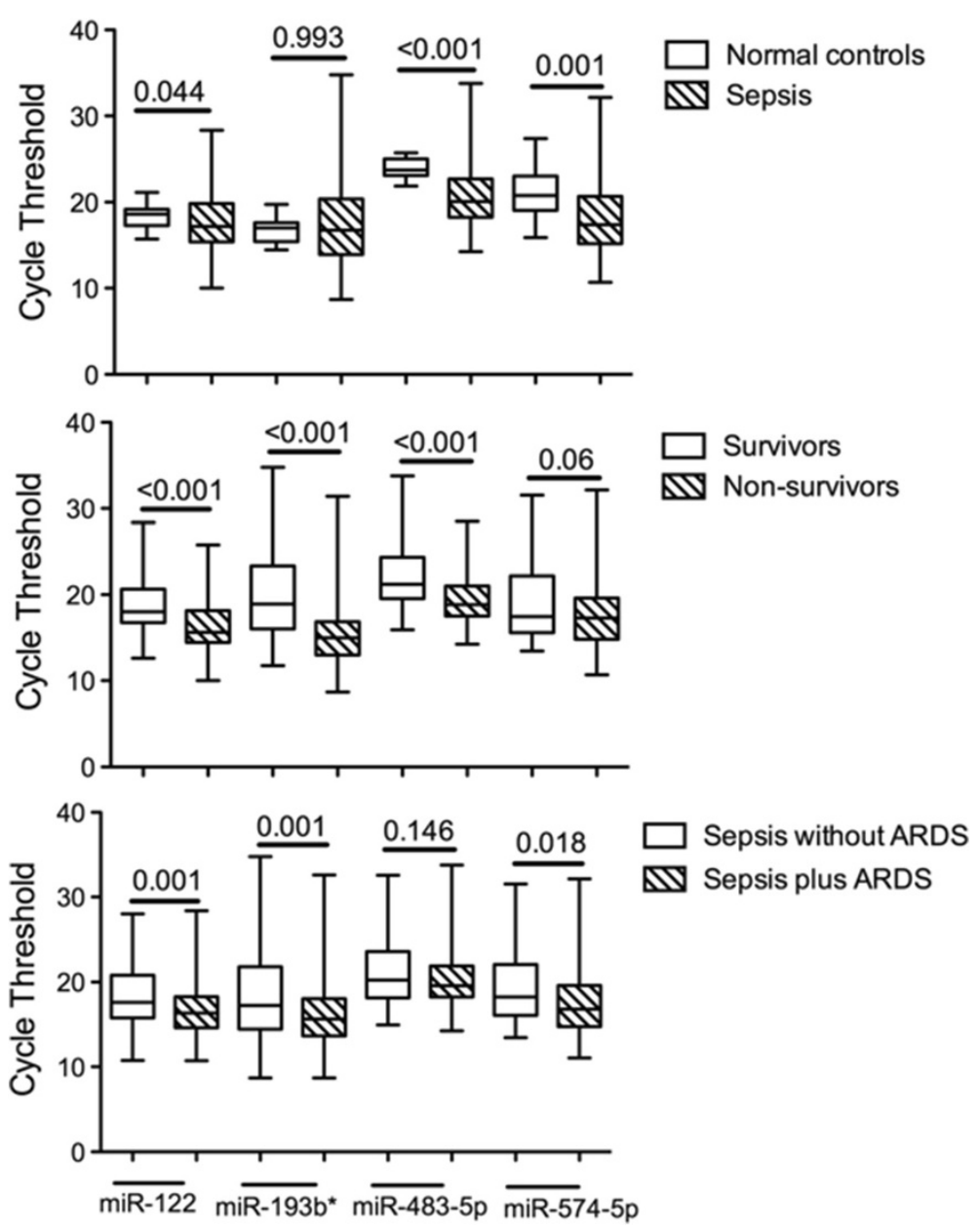

Figure 1 Cycle thresholds of the four microRNAs (miRNAs) in the three pairs of groups. ARDS, acute respiratory distress syndrome.

Table 3 The association between miR-122 levels and 28-day mortality in sepsis patients

\begin{tabular}{|c|c|c|c|c|}
\hline & All patients $(n=232)$ & $\operatorname{RICU}(n=67)$ & SICU $(n=121)$ & $\operatorname{EICU}(n=44)$ \\
\hline \multicolumn{5}{|c|}{ Odds ratios of miR-122 $(95 \% \mathrm{Cl})$} \\
\hline \multirow[t]{2}{*}{ Unadjusted $^{a}$} & $0.775(0.703,0.853)$ & $0.776(0.664,0.908)$ & $0.77(0.662,0.894)$ & $0.764(0.610,0.956)$ \\
\hline & $P<0.001$ & $P=0.001$ & $P=0.001$ & $P=0.019$ \\
\hline \multirow[t]{2}{*}{ Adjusted $^{\mathrm{b}}$} & $0.789(0.713,0.872)$ & $0.777(0.663,0.911)$ & $0.763(0.655,0.888)$ & $0.650(0.474,0.891)$ \\
\hline & $P<0.001$ & $P=0.002$ & $P<0.001$ & $P=0.007$ \\
\hline Adjusted $^{\mathrm{b}}+$ & $0.772(0.690,0.863)$ & $0.781(0.665,0.918)$ & $0.791(0.677,0.925)$ & $0.631(0.448,0.890)$ \\
\hline SOFA score & $P<0.001$ & $P=0.003$ & $P=0.003$ & $P=0.009$ \\
\hline Adjusted $^{\mathrm{b}}+$ & $0.815(0.734,0.905)$ & $0.709(0.578,0.870)$ & $0.753(0.639,0.887)$ & $0.622(0.431,0.897)$ \\
\hline APACHE II score & $P<0.001$ & $P=0.001$ & $P=0.001$ & $P=0.011$ \\
\hline Adjusted $^{\mathrm{b}}+$ & $0.812(0.724,0.911)$ & $0.868(0.647,0.967)$ & $0.721(0.599,0.867)$ & $0.376(0.133,0.865)$ \\
\hline ARDS & $P<0.001$ & $P=0.023$ & $P=0.001$ & $P=0.034$ \\
\hline \multicolumn{5}{|c|}{ The predictive value of miR-122 } \\
\hline $\mathrm{AUC}(95 \% \mathrm{Cl})$ & $0.732(0.665,0.799)$ & $0.763(0.65,0.877)$ & $0.706(0.611,0.802)$ & $0.770(0.574,0.966)$ \\
\hline$P$-value & $<0.001$ & $<0.001$ & $<0.001$ & 0.009 \\
\hline Sensitivity & $79.5 \%$ & $75.9 \%$ & $79.4 \%$ & $80 \%$ \\
\hline Specificity & $63.5 \%$ & $70.3 \%$ & $60.7 \%$ & $81.8 \%$ \\
\hline
\end{tabular}

${ }^{\mathrm{a}}$ Unadjusted by any value. ${ }^{\mathrm{b}}$ Adjusted by age and gender. APACHE, Acute Physiology and Chronic Health Evaluation; ARDS, acute respiratory distress syndrome; AUC, are under the curve; EICU, Emergency Intensive Care Unit; RICU, Respiratory Intensive Care Unit; SICU, Surgery's Intensive Care Unit; SOFA, Sequential Organ Failure Assessment. 


\section{Abbreviations}

APACHE: Acute Physiology and Chronic Health Evaluation; ARDS: Acute respiratory distress syndrome; CRP: C-reactive protein; miRNA: microRNA; PCT: Procalcitonin; SOFA: Sequential Organ Failure Assessment.

\section{Competing interests}

The authors declare that they have no competing interests.

\section{Authors' contributions}

HW and BY had full access to all of the data in the study and take responsibility for the integrity of the data and the accuracy of the data analysis and performed the experiments. They designed the study, analyzed data and wrote the manuscript. LX and YJ designed the studies, analyzed data and edited the manuscript. JD had full access to all of the data in the study and takes responsibility for the integrity of the data and the accuracy of the data analysis.

\section{Acknowledgements}

This work is supported by the general program of the National Natural Science Foundation of China (81170008), and the general program of China's 12th Five Year Plan and its military (CWS11 J094).

\section{Author details}

'Department of Respiratory Medicine, Chinese PLA General Hospital, 28th Fuxing Road, Beijing 100853, PR China. ${ }^{2}$ Department of Respiratory and Critical Care Medicine, Beijing Chao-Yang Hospital, Beijing Institute of Respiratory Medicine, Capital Medical University, Beijing 100020, China. ${ }^{3}$ International Medical Center, The General Hospital of Chinese People's Liberation Army, Beijing 100853, China. ${ }^{4}$ Department of Respiratory Medicine, Beijing Nanyuan Hospital, Beijing 100076, China. ${ }^{5}$ Division of Pulmonary and Critical Care Medicine, Brigham and Women's Hospital, Harvard Medical School, Boston, MA 02115, USA.

\section{Published online: 12 December 2014}

\section{References}

1. Brunkhorst FM, Engel C, Bloos F, Meier-Hellmann A, Ragaller M, Weiler N,

Moerer O, Gruendling M, Oppert M, Grond S, Olthoff D, Jaschinski U, John S, Rossaint R, Welte T, Schaefer M, Kern P, Kuhnt E, Kiehntopf M, Hartog C, Natanson C, Loeffler M, Reinhart K, German Competence Network Sepsis (SepNet): Intensive insulin therapy and pentastarch resuscitation in severe sepsis. N Engl J Med 2008, 358:125-139.

2. Wang H, Zhang P, Chen W, Feng D, Jia Y, Xie L: Serum microRNA signatures identified by Solexa sequencing predict sepsis patients' mortality: a prospective observational study. PLoS One 2012, 7:e38885.

3. Wang H, Meng K, Chen W, Feng D, Jia Y, Xie L: Serum miR-574-5p: a prognostic predictor of sepsis patients. Shock 2012, 37:263-267.

4. Levy MM, Fink MP, Marshall JC, Abraham E, Angus D, Cook D, Cohen J, Opal SM, Vincent JL, Ramsay G: SCCM/ESICM/ACCP/ATS/SIS International Sepsis Definitions Conference. Crit Care Med 2001, 2003:1250-1256.

5. Starkey Lewis PJ, Dear J, Platt V, Simpson KJ, Craig DG, Antoine DJ, French NS, Dhaun N, Webb DJ, Costello EM, Neoptolemos JP, Moggs J, Goldring CE, Park BK: Circulating microRNAs as potential markers of human drug-induced liver injury. Hepatology 2011, 54:1767-1776.

6. Wang HJ, Deng J, Wang JY, Zhang PJ, Xin Z, Xiao K, Feng D, Jia YH, Liu YN, Xie LX: Serum miR-122 levels are related to coagulation disorders in sepsis patients. Clin Chem Lab Med 2014, 52:927-933.

doi:10.1186/s13054-014-0704-9

Cite this article as: Wang et al:: Serum miR-122 correlates with short-term mortality in sepsis patients. Critical Care 2014 18:704. 